\title{
The Ecological Economics Revolution: Looking at Economics from the Vantage-Point of Wittgenstein's and Kuhn's Philosophies
}

Rupert Read $1 \square$

Email R.Read@uea.ac.uk

1 School of Politics, Philosophy, Language and Communication Studies, University of East Anglia, Norwich Research Park, Norwich, Norfolk, NR4 7TJ, UK

\section{Abstract}

The abstract is published online only. If you did not include a short abstract for the online version when you submitted the manuscript, the first paragraph or the first 10 lines of the chapter will be displayed here. If possible, please provide us with an informative abstract.

Is there a scientific revolution taking place in economics? This piece seeks to apply the thinking of Wittgenstein and of the major philosopher of science who was, I have argued elsewhere.

\subsection{Overview}

Is there a scientific revolution taking place in economics? This piece seeks to apply the thinking of

Wittgenstein and of the major philosopher of science who was, I have argued elsewhere, ${ }^{1}$ most influenced by him-Kuhn — to the emergence of 'ecological economics'. (This is a topic of not-inconsiderable importance, given the power of economics in our world today, and the role of conventional economics in degrading the Earth, a degrading which is now threatening to put not just myriads of other species but humanity itself 'out of business'.)

Due to the financial/economic crisis of the last decade, Economics itself ought to be in profound crisis and rebirth. It does not seem to be, despite the apparent flux due to 'behaviourial economics' etc. But, at a slower pace, there might be a paradigm-shift taking place in economics: the (slower, much deadlier) ecological crisis seems gradually to be yielding a green or ecological economics.

This chapter will investigate what Wittgenstein's philosophy has, implicitly, to say about this situation. Is the fantasy of 'progress', as critiqued by Wittgenstein, a key motivation for the dream of a scientific economics? Is scientism, as also critiqued by Wittgenstein? I will (also) investigate what Kuhn's (broadly Wittgensteinian) philosophy has to say about this situation. Is economics the kind of thing that Kuhn famously terms a 'discipline without a paradigm'? Does it/could it have a scientific status? (Insofar as it does, or could, does the emergence of ecological economics around Herman Daly et al. relevantly resemble (say) the Chemical revolution around Lavoisier et al.?)

My conclusion is double: That, insofar as economics does or could have scientific status, then one might justly say that the ecological economics revolution is or could be a real scientific revolution. But, and superordinate to this point, that there remain significant (broadly Wittgensteinian and Kuhnian), probably unovercomeable reasons to believe that it is misleading even to aspire to have a scientific economics- 'even' 
from within the standpoint of a scientifically-respectable ecology. Economics does not and probably never will have scientific status. This means that attempts to 'be scientific' within economics are liable to be pointless. Rather, we should seek to understand economics principally as something else, and something needful and well worth having: especially, as politics and as philosophy, operating within the limits of (natural) science (the limits imposed by ecology; i.e. by the Earth).

\subsection{How to Make Economics into a Science...?}

Economics, as Philip Mirowski has taught us, was 'made' into a 'science' by the crude expedient of directly copying the paradigm of (the frontiers of) science in the mid-nineteenth century, mechanics. In the twentieth century, there have been numerous efforts to 'correct' this model, to make it more scientific. Perhaps the most impressive and plausible has been the effort by Robert Costanza to integrate economics with real science, in particular with the environmental sciences - and in particular to value economically the biosphere. My suggestion will be that, on balance, this move nevertheless points in precisely the wrong direction.

However, I will further suggest below that if we rotate the axis of our examination of economics, we can come to see the contribution of Costanza et al. in a quite different light. In this light, it appears, not as a way of making economics genuinely scientific at last, but as a way rather of showing economics to be what, I contend, it really is or at least ought to be: a subset of Ecology and of Politics/Labour Studies (or-perhaps better-simply a subset of ecology, human and non-human), a subset with in fact a peculiarly philosophical face. This takes economics back to its roots in the great works of such economic philosophers as Marx, Smith, the Physiocrats, and so on. Or even, as one might put it, before those roots: to political economy as a craft, an art, and a way of thinking about life. On this understanding, we are beyond the idea of economics as a science. Rather, economics gives way to environmental science and to political economy, and what insights if any it offers 'of its own' become primarily non-quantitative, transitional, broadly philosophical insights. (Just as, as we will see, Kuhn at his best would lead us to expect.)

For: it is an unjustly-neglected fact, and one of potentially-immense philosophical and political and ultimately practical significance, that neo-classical economics originated, in the work of Jevons and Walras, by means of an appropriation of nineteenth century physics. Specifically, that the creation of neoclassicism involved the transformation of Helmholtzian energy-conservation principles into the 'general equilibrium' principles of the conservation of utility. ${ }^{3}$ This creation of allegedly-scientific economics was accomplished in remarkably direct fashion: the mechanics equations in question were kept intact, and what the variables stood for was simply substituted, economic variables for physics variables. Thus economics seemingly attained the legitimacy of a science: it mathematicised itself by presenting itself as a strict analogue for physics. The 'laws of economics' were then supposed to apply just as rigorously to 'social atoms' as the laws of physics did to physical atoms. At each stage in the growth of the economy, a new equilibrium was supposed to have been attained: no limits were present, then, to the figures one could plug into these equations, representing now not energy but utility.

AQ1

My own view, already argued elsewhere, ${ }^{4}$ is that the self-identification of economics as a science has proven disastrous to academic and intellectual inquiry, to the world, and (in the very long run) to economics itself. My view, following Kuhn, would be in particular that the leap to numbers, to quantification, prior to a serious effort qualitatively truly to understand the economic world, is deeply suspect. (And this is already a worrying precedent for Costanzian ecological economics.)

Let me now explain this.

\subsection{Social and Economic 'Science'?}


Drawing extensively on Wittgenstein, I've argued over the years in a series of books ${ }^{5}$ that the trouble with the categories of 'social/human/economic science' is that they are an apeing of science. Acting as if you have a paradigm in Kuhn's sense, when you actually don't.

The most common way in which this apeing occurs is through a numbers fetish. A premature effort to quantify one's discipline. With garbage in, and so garbage out....

Here is the opening of perhaps the most seminal of all Kuhn's critiques of the urge to go forth and quantify:

"At the University of Chicago, the façade of the Social Science Research Building bears Lord Kelvin's famous dictum: "If you cannot measure, your knowledge is meager and unsatisfactory." Would that statement be there if it had been written, not by a physicist, but by a sociologist, political scientist, or economist? [I suspect that] the answer to [this question] is no... Because physical science is so often seen as the paradigm of sound knowledge and because quantitative techniques seem to provide an essential clue to its success, the question how measurement has actually functioned for the past three centuries in physical science arouses more than its natural and intrinsic interest. Let me therefore make my general position clear at the start. Both as an ex-physicist and as an historian of physical science I feel sure that, for at least a century and a half, quantitative methods have indeed been central to the development of the fields I study. On the other hand, I feel equally convinced that our most prevalent notions both about the function of measurement and about the source of its special efficacy are derived largely from myth.",

Kuhn goes on to suggest that the key to understanding why this is, and overcoming the myth that has long had 'social scientists' in its thrall, is to understand that it is only if one achieves a new qualitative understanding, of the kind arrived at when a scientific revolution occurs and institutes a new paradigm (exemplar) at the heart of its fresh puzzle-solving normal scientific activity, that a quantitative understanding can develop and be of any use. (A paradigm of this - to which we will return-was for Kuhn the Copernican Revolution in astronomy. Copernicus gave us a new, perspective-revolutionising, simple qualitative understanding of our place in the universe. His calculations by contrast were for a long time inferior to Ptolemaic calculations (mainly because he assumed that the paths of the planets were circular, rather than elliptical).)

The dread temptation that has lured economics down the path of scientism is of course that it has a readymade quantification to hand. Money preceded economics!

Economics typically aims at a scientificity that perpetually eludes it because it quantifies before it has arrived at a fundamental qualitative understanding.

With regard then to economics and science, then, once one has admitted the stark almost uncontroversial obviousness of economics's scientific inefficacy to date (exemplified in the utter failure of mainstream economics to predict the financial crisis, and in fact rather to facilitate it), two opposite options present themselves:

(1) We could seek to make economics more scientific; genuinely scientific.

(2) We could admit that economics is not a science. That it is value-saturated, and needs to be pluralistic, in ways that biology is not, even once we have (as we should) re-understood biology in the kind of way recommended by John Dupre.

Now, I respect the impetus behind (1). And I am fully in favour, as I will explain, of making economics more 
compatible with science.

Moreover, I am 100\% against the impression that might be given by (2) that there is nothing to be said for a change of pre-analytic vision in economics. On the contrary, I believe that economics desperately needs the new Earth-centred pre-analytic vision that Herman Daly has repeatedly proposed as a new foundation for economics. That is the ecological economics 'revolution'. But the question I am raising is whether that revolution would genuinely be a scientific revolution in Kuhn's sense. And whether the new Earth-centred pre-analytic vision of planetary limits etc. should be considered therefore a paradigm. I am suspicious of that idea, and a key aim of the present piece is to convey the reasons for that suspicion.

Wouldn't it be simpler for me simply to urge that economics undergoes a Copernican revolution? One that decentres humanity, as we were decentred from our place at the centre of the Universe by Copernicus.

Wouldn't this be exactly the kind of qualitative improvement stressed by Kuhn? If, instead of the diagrams by way of which students are introduced to economics, diagrams constructed around human needs, picturing an endlessly expanding economy to which the ecosystem is a kind of externality or addendum (see e.g.

Figure 26.1), we moved to a richer picture which sees the ecosystem as the limit and encompasser of a much 'smaller' subsystem, the economy (see e.g. Figure 26.2):

\section{Fig. 26.1}

Sourced from Feasta under a creative commons attribution-noncommercial-ShareAlike 3.0 unported license 


\section{ECOSYSTEM AS SUBSYSTEM OF MACROECONOMY}

\section{ECONOMY}

Fig. 26.2

Sourced from Feasta under a creative commons attribution-noncommercial-ShareAlike 3.0 unported license 


\section{A MACRO VIEW OF THE MACROECONOMY}
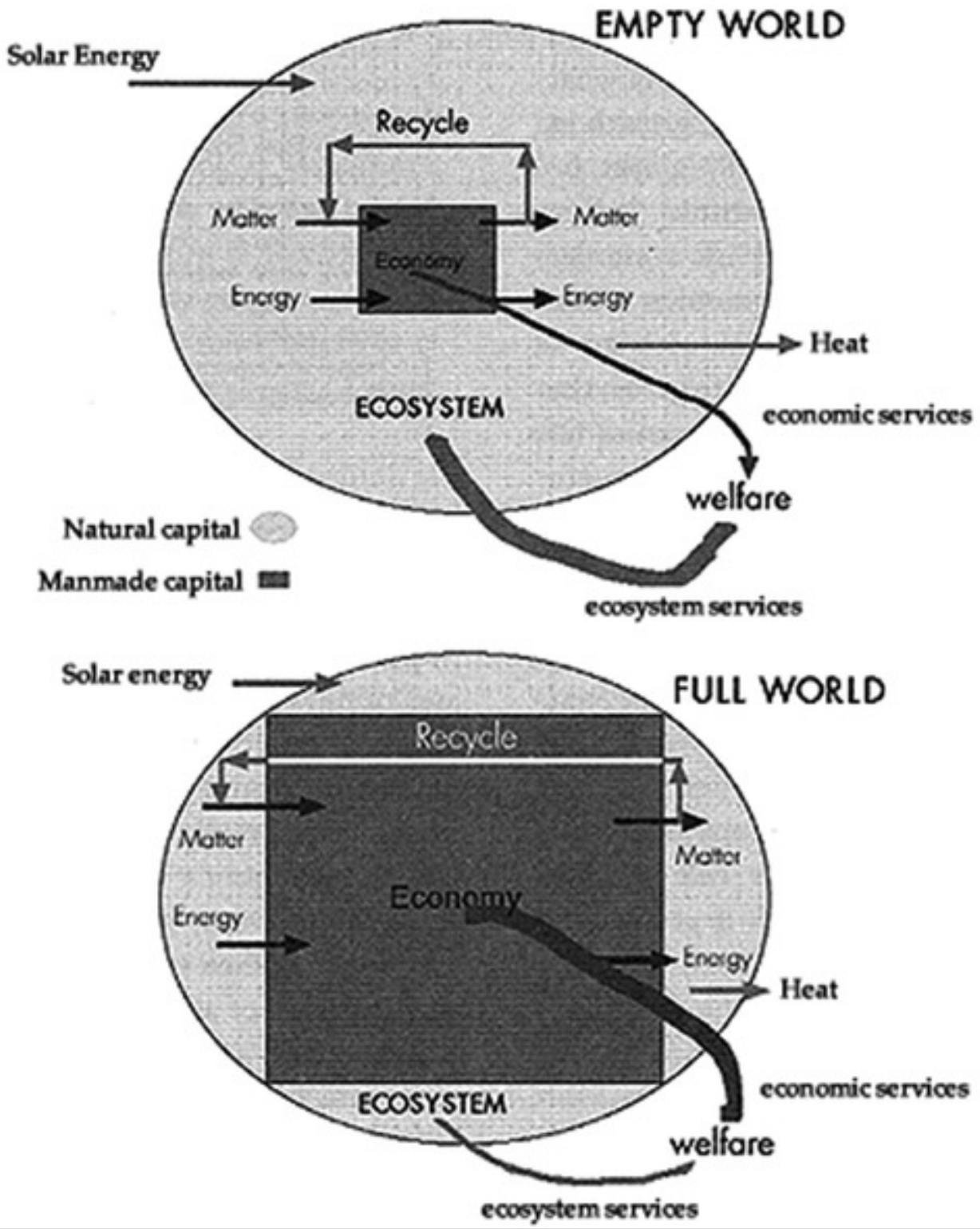

AQ2

My reluctance to cave into the temptation to see the ecological economics 'revolution' as a scientific revolution pure and simple — one which, like the Chemical Revolution did for chemistry, establishes economics on the secure path of scientificity for the first time, by moving from Figs. 26.1 and 26.2, - can only be fully understood once we go further into the hazards of the endeavor to arrive in the kind of way that Costanza did at a quantitative ecological economics, and picture instead a way of seeing economics through the lens of energy (the lens Costanza recommends) which we will be less tempted to regard scientistically.

\subsection{Quantitative Ecological Economics?}

The modelling of economics on mechanics, specifically on energy-conservation principles, a modelling which has been of incalculable rhetorical significance and has had vast intellectual and real-world effects, as 
can be seen writ large in the works of such luminaries as Samuelson, and as exposed to the cold light of day in the work Mirowski and others, can actually shed a good deal of light on the nature of ecological economics.

The particular apeing of physics that we find in neoclassical economics has proven so effective (I mean in terms of being adopted; I don't mean scientifically effective) in part because it actually does key into one deep similarity. Go back from the idea of utility to the idea of energy - and then an environmentally-centered economics makes broad sense. There is a real sense-if one stretches the concept of energy as far as it can possibly go (and so empties it of scientific content - see below) - in which the founding equations of neoclassicism get something very important right. But only because what economics needs to understandand what neoclassicism systematically shields from view-is that it, economics, is (or rather, must be, ought to be) nothing other than the study of all the producers of or vehicles of energy, in the broadest sense of that word: encompassing for instance not only fossil fuel energy and renewable energy, but also the energy provided by the labour of animals, including crucially of course the labour of probably the most vital economic animal of all, humankind. That is, of energy (in the ordinary sense of the word) and ecology (i.e. both the finitude of non-renewable energy and the finitude of Earth's natural resources and of the capacity of the Earth to absorb pollution), and of the 'energy'-contributions of human and non-human-animal actors and of technological change. And so on.

This would of course require a complete revolution in the practice of economics.

Is what I am saying this: That if economics were to take seriously the origins of the equations which birthed neoclassicism, then, maybe it might be scientific after all? Possibly: But I think not quite. For what would it be? It's environmental science (and perhaps 'ecological economics' - see below) which take seriously the study of energy sources and the hazards attending their mass use: economics would then in effect be a human- and societally- oriented branch of a widened environmental science, and would be exposed to the limits which the latter centres (or ought to centre) its investigations on. I.e. The planetary limits (and social limits to growth, and so forth). It would no longer be able to hold out the mad prospect of indefinitelyprolonged 'growth'; it would have to give up the equations which founded it altogether except insofar as they were radically reconceived to include all that had been previously excluded as mere 'externalities'. And this inclusion would have to be done not in monetary terms, but in terms of the manifold of energy, impact, sustainability, and so on. I.e. It would be economics that was subsumed into ecology, not vice versa.

The way that the economic valuation of nature has proceeded (in Costanza and his many successors in 'natural capital' valuation) has been to try to assimilate nature to (economic) capital, rather than vice versa. This, I am suggesting, is very troubling.

Furthermore: economics which took seriously that it is about labour and the use of animals and so on too would have to recognise not only their limits but also their sufferings and tragedies (and joys etc.). It would be open to the downsides for its 'objects' of for instance growth—such as, perhaps, greater stress, greater exploitation, less free time, more sickness. It would have to consider the problematic consequences of increasing 'use of human (or other animal) energy'. For, rather than abstracting from these, as one does when one simply assumes that utility is growing as the economy grows, it would have to look and see whether that was in fact the case. (The Index of Sustainable Welfare, the Genuine Progress Indicator etc. are perhaps a first tentative step in this direction. But even these, we should be suspicious of. We should be deeply suspicious of any effort, however well-intentioned, however 'complete', however 'scientific', that seeks to reduce the entire economy, let alone the broader society, with all its incommensurables, to one number.)

What this all amounts to is that, from the point of view for instance of labour or of ecosystems-and actually these combine, in the concept of ecology as including human ecology 8 -we don't have (as of course we do in 
physics) a conservation of energy, except in the exceptional (desirable) case when we practice (human) ecology in the normative sense of the word, behaving with ecosystemic rectitude and treat people aright, etc. When for instance we use almost exclusively genuinely renewable energy, rather than fossil fuels or nuclear (for the latter, just like fossil fuels, is non-renewable (depending on finite fuel sources) and dangerously polluting); and when we don't abuse labour or animals. We might then put the point this way: for (post-neoclassical) economics to really be true, it would have to become the study of and respect for labour (and, as Polanyi reminded us in his great work The great transformation, labourers are also of course actually citizens, people) and for the entirety of our ecosystems. Economics must decisively lose its absurd sense of itself as (the study of) a Pareto-optimal pseudo-closed system. A closed circuit of exchange of goods and services. For it is completely open to (the implications of) the finitude of our world-and all that is in it. When we construe labour as energy, for instance, then, as implied above, its increase does not yet register as the cost it probably is to the quality of life of the labourer(s). When we construe fossil fuel energy only as energy, too, its increased use does not register as the cost it certainly is to future generations. The physical universe (though not the Earth, because of the Sun), from whence the conservation principles came, is (roughly) a closed system. For the economic system to characterize itself similarly is for it to ignore its through-and-through embeddedness in and co-constitutiveness with the environment-with the entire planetary ecosystem - which only works effectively as a semi-closed system open to the flow of solar energy when it is both lucky and is run well by its denizens/citizens. 'Run well', in the sense not necessarily (or rather: almost necessarily not) of the logic of actually-existing neoclassical economics, nor even of any souped-up quantitatively-improved version of it, but rather in the far subtler and wider and still-less measurable logic of the happiness and integrity in inter-relatedness of the creatures of the world, including of future generations. For if we think of the world as a finite whole, as ecosystemic thinking-but not of course neoclassical economic thinking — demands, then included in that whole are all the generations as yet unborn, too....

When one thinks through then what it would take to be able to take seriously an understanding of economics as potentially involving a kind of conservation of 'energy', one sees that it will among other things involve recapturing lost greatness in the economics that came before the triumph of neoclassicism. For example, a return to what insights were present in 'the labour theory of value' (which reached its apogee in Marx ${ }^{10}$ ) and in land theories of value (e.g. the forgotten work of the Physiocrats). But it is not, I submit, a theory of value that we really require, not even one which intelligently 'combines' the (value of and in the) labour of humans and animals, the energy extracted from the Earth in fuel-form, and so on, into an ecological synthesis.

To see why I say this, it is worth looking further at some of the most important work done by the influential founding 'ecological' economist: Costanza. Costanza tried in 1980 to develop an 'energetic' theory of value. That is, he tried to convert not only natural resources but also labour and even government services into energy equivalents (Here we see why any assumption that total literal quantification of energy in the economic sense might be possible by commensurating it as in for example the old concept/unit of 'house power' would be in vain). He claimed that his results showed that inputs of energy values are extremely closely correlated to outputs of monetary values.

One way this effort might be seen is as an (extremely-valuable and much-needed?) effort to internalize the ecosystem, labour etc. into economics... But is that actually what is needed? Or should things rather, as I intimated above, move the other way: should economics be subsumed into the study and understanding of ecology, of labour, and indeed of political understanding and action?

Of course, Costanza's work that attempted to reduce everything to energy should be distinguished from his even more famous work that attempted to reduce everything to money, to price the 'natural capital' of the entire world. But he is hardly in a good place from which to object to a way that I may seem here to have run these two things together; because, as just outlined, he tends to run them together, himself! 


\subsection{On the Roots of the Dangerous Delusion of Measuring 'Natural Capital'}

Is Costanza's analysis an alternative to neoclassicism, showing up its limitations or blindspots? Or is it a correction to it; does it merely put neoclassicism right where it had gone a little wrong? Or is it even the bringing of neoclassicism to full self-consciousness? Is Costanza's achievement actually to show what it would be to take seriously the founding intuition of neoclassicism - that economic activity IS energy-, while retaining neoclassical pricing methodology and the concept of equilibrium?

My own suspicion is that the latter is very close to being the truth. I think that Costanza's 'energetic' theory of value is precisely of a piece with his pricings of the atmosphere, of the sea, of the entire ecosystem of our planet. His 'Promethean' would-be valuation of the totality of natural capital. I regard the latter as an obscene triumph of the logic of neoclassical economics, not as any kind of alternative to it. ${ }^{11}$ It seems to me that ecological economics has yet to decide whether it is really ready to put ecology and human life first, or whether it is merely a kind of adjunct to-in fact, a completer of, a more efficient and grander, more total version of-neoclassicism.

In a way, then, Costanza is deepening our difficulties, not solving them. He inappropriately tries to make economics more scientific, by including factors that it has excluded.

The effort to price 'natural capital' (or 'ecosystem services') in effect contends that we can scientifically analyse the entire planetary ecosystem and convert it into money. That the category of capital is superordinate to the category of nature. That money is more important than life. This is a bizarre destiny for what was meant to be an ecological economics.

But, if Costanza saw what he was wanting to do in the alternative philosophical light that I am developing here, he would see that there is another possible way of following up the 'energetic' insight with which he began. For when one takes seriously the sense in which energy (in a broad enough sense of the word) just is identical with economic activity, without attempting to theorize or scientise this insight, then one sees that actually one's insight is not and could not be best characterised as a piece of science nor even theory. It is rather 'just' a way of seeing —a 'point of view, 12 - a perspicuous, helpful and insightful more or less philosophical (in Wittgenstein's sense) way of recovering a way of seeing that economic ideology can get in the way of. Of course economic activity is ((describable/readable as) meetings of and various forms of) energy - one might even justly wonder what else it could possibly be? And now one will be much more able-better primed - to look at what counts so much for us, at this point in history - the impact of these employments of energy, upon our quality of life, upon the liveability of the planet for future generations, and so on. The things which neoclassicism has little or no conceptual space for. Which it treats, ludicrously as 'externalities'. Bringing those 'externalities' inside a system that is set up fundamentally on the wrong basis is not progress, it is the making seemingly coherent of something monstrous.

It won't make sense to do what Costanza wanted to do: literally to quantify these things. (The wide bringing together under the heading of 'energy' that I've briefly and speculatively carried out is not a commensuration, let alone a mensuration, let alone the basis of a quantification. Because life is incommensurate with non-life, for starters.) But that's just as well: for that attempt at quantification was pretty absurd or just repellent to begin with. To quantify the value of what sustains life is as nonsensical as it is abominable: infinite value is of an altogether different order to finite (genuinely quantifiable/measurable) value; infinity is not a number. Likewise: Costanza's 'result' that inputs of energy value are closely tied to outputs of monetary value is a fake piece of (pseudo-)'science': for when everything is reduced to energy, of course there is a virtually constant relationship between energy and output! The contribution to growth of labour, government etc. is computed by reference to the output-so there is only a fake appearance of 
something having been explained here. ${ }^{13}$ Costanza's famous pricing of the world's ecosystem services is in this way based in a dangerous piece of metaphysical pseudo-science. Because it is only the illusion that we can assimilate everything natural into one thing whether that be energy or money, that enables his pricing to seem possible.

Economic activity 'is' energy: but this is not a basis for any kind of science, but only a reminder of something ${ }^{14}$ —or, rather, of a whole lot of things — that only a scientistic ideology could have caused us to forget, in the first place. Value can't truly be theorized - this deep truth, Costanza doesn't seem to have realized, any more than Marx did. But their ideas have the germ in them of profound philosophic reminders to us. ${ }^{15}$ Being reminded of the ineradicable contributions of labour, of (now in the ordinary sense) energy, etc., to the economy is a portion of the study of — and the realization of — who we are, what we really want and need etc.; with us (humans) understood as utterly embedded in and co-constitutive with nature.

Where do otherwise promising 'ecological economists/philosophers' such as John Gowdy ${ }^{16}$ and Robert Costanza most deeply go wrong? In hoping for quantifications of the value of nature and/or scientific appraisals or theorizations of its value. For these hopes embody incoherent goals. Science cannot tell us anything about nature's value. (And attempts to quantify it will always underestimate nature's value for unknowably-distant future generations, who are typically 'discounted' to some extent in the calculations even of ecological economists. A true steady-state economics is needed. With-contra Costanza's famous, catastrophic allowance of a discount rate of approx. $2 \%$ p.a. ${ }^{17}$-no discounting.)

When we think of economic activity/growth etc. as essentially dependent upon energy in the expanded sense of that term which I outlined above, then it doesn't mean anything any more to characterise that concept, "energy", as the focus of a science. Far from it. The concept of "energy" no longer has quantifiable content: it cannot be measured as Costanza wished to measured it, nor used in equations as standard neoclassicism wish in effect to use it (to 'index' utility or its positivistic successor-concepts). It is conceptually unmeasurable. It is empty, from the point of view of any self-respecting science. Rather, what we have in our hands, in this expanded concept of "energy", is the focus of - the nub of - a philosophical insight. That returns us to the land, to labour, and so on. To this world, where we find the real—and perilously open-systemed—economy. An economy that is a subset of society, and that depends on societal (and ultimately, on philosophical) valuation.

We have seen then that economics was made into a 'science' by the crude expedient of directly copying the paradigm of (the frontiers of) science in the mid-nineteenth century, mechanics. This copying was wellcontested by real scientists at the time, but to no avail. ${ }^{18}$ Nor was it of any avail when physics moved on, as it swiftly did-e.g. the Second Law of thermodynamics, letalone quantum mechanics, have seemingly barely been noticed by the 'scientific' economists who have utterly dominated their discipline, to date. In the twentieth century, various efforts from within economics to contest this 'scientific' model have been fought in the trenches, or co-opted, (or arguably both, in the important case for instance of Keynes). There have also been very numerous efforts to correct the model, to make it more scientific. One of the most interesting of recent times has been the influential effort by Robert Costanza et al. to integrate economics with real science, in particular with ecology and the environmental sciences in general. My suggestion above however is that this move, at least as it has been attempted thus far, points in precisely the wrong direction. No effort to save the scientific status of economics which does not entirely give up the starting point of neoclassicism will have any lasting effect, and such efforts, especially if intelligently carried out, with attention to what does indeed need to be attended to (e.g. the ecological crisis), are merely particularly-dangerous obscurers of this truth. Such is my assessment of the 'movement' for economic valuation of natural capital and ecosystem services.

However, I suggested also that if we rotate the axis of our examination of economics, we can come to see the contribution of Costanza in a quite different light. In this light, it appears, not as a way of making economics 
genuinely scientific at last, but as a way rather of showing economics to be what, I contend, it really is or at least ought to be: a subset of Ecology and of Politics/Labour Studies (or-better-simply a subset of ecology, human and non-human) a subset with in fact a peculiarly philosophical face. This takes economics back to its roots, in the great works of such moral philosophers as Marx, Smith, the Physiocrats, and so on. On this understanding, we are beyond the idea of economics as a science. Economics must be compatible with science; and at present it is not. But if we try to make it into a science, we end up with the absurdities of Costanzianism. I've suggested that the way out of those absurdities lies via philosophical rethinking in a broadly Wittgensteinian mold.

Rather than itself becoming a science, then, the optimum solution is for economics as we currently know it to give way to environmental science and to political economy, and what insights it offers 'of its own' become chiefly non-quantitative, transitional, philosophical insights: like the insight, which is really just a way of reminding ourselves of what is so obvious, so constantly in view, that we are inclined to look through it and forget it, ${ }^{19}$ that there can be no economic activity without one kind or another of 'energy', and a fortiori that economic growth tends of course to requires an increase in such 'energy'. And then the only truth in neoclassicism is this, seen through a glass darkly. The equations that neoclassicism borrowed from physics then become bearers of insight after all: but they point precisely, now, not to economics as a free-standing science, but quite beyond this idea. They point, in fact, to the absurdity of the growthist hegemony and to the beginnings of an alternative: to the world that we all always already know (so long as ideology doesn't delude us about it); to the improvement of our knowledge that comes from real, natural science (especially, ecology); and to philosophical understanding itself. Understanding of the kind essayed, for example, in the present chapter. And thus to the possibility of us deciding together what kind of economy to have, within the limits that nature sets for us.

\subsection{Wittgensteinian Conclusions}

As I understand him, ${ }^{20}$ Wittgenstein is above all a philosopher of intellectual freedom. He teaches us that our thinking is constantly constrained by the scribblings of dead philosophers, and that, to escape such influences, we have to make them conscious. Once we do so, as I have sought to do in this piece, then we can choose our path adequately at last.

I propose that we exercise our philosophical freedom not by creating new theoretical edifices-such as a genuine science of economics would supposedly be-but by taking the bold step of actually making explicit and then questioning the hegemony of science (i.e. the step of questioning scientism).

We saw in this chapter that there are two rival visions of ecological economics available:

(1) On the Costanzian vision, we seek to internalize externalities in full. This is the most superficially obvious way for a Kuhnian to go, in relation to economics. It would be exemplified by Costanza's famous valuation of the total value of the world's 'ecosystem services'.

(2) If, by contrast, we take Herman Daly's vision of ecological economics, as based in a quite distinct pre-analytic vision, seriously, and truly place Earth (and the Sun!) at the centre of our thinking, while recognizing that Earth has simultaneously to be thought as far more than a rock-i.e. recognizing that the reason the Earth matters is because of the beings (not just humans!) inhabiting it - then a different philosophical path opens up before us. One leaving intact the sociality and politicality of economics. And constraining economics tightly by way of natural science, and particularly of ecology (which, as Teddy Goldsmith labored to show us, ${ }^{21}$ is actually far more than a natural science!). This is a subtler way to think Kuhn in relation to economics, a way not presuming that economics 'really is' a science. And rather, taking inspiration from Kuhn's legitimation of many 
ways of knowing that are non-scientific.

Route (1), I have suggested, fails, for Kuhnian reasons: because there is an inadequate qualitative understanding of the world, in the 'paradigm' of neoclassical economics; and all that Costanza ultimately does is to seek to correct that paradigm. Not to transcend it.

The terrible irony of the neoclassical system of economics is that if models its subject metaphorically on the conservation of energy but ignores the literal truth of the laws of thermodynamics. Entropy is a fatality for endless growth. Costanza tries to correct this failing. But it would be better to junk the whole failed vision. Substituting a better one; but without leaping to the conclusion that this better green ecological vision of economics is a vision literally of a science.

\subsection{Envoi: A Policy-Alternative to the Scientism of 'Natural Capital' and 'Ecosystem Services'?}

What, then, is the alternative to a fake scientisation of economics? If the now-widely-influential Costanzainspired idea of measuring the economic value of 'ecosystem services' is based in pseudo-science, and ought to be replaced by a deeper effort to politically and ecologically philosophise a world that could last, what form should the latter effort take?

That is a task for another paper. But let me make one concrete proposal. One of the gravest dangers of the economic valuation of natural capital or ecosystem services is that it encourages us to think that we now know the value of any 'chunk' (sic) of nature. In relation to 'natural capital', a precautionary approach by contrast clarifies that it is reckless ever to assume that the purported worth in monetary terms of some chunk of nature/farmland actually exhausts its worth. Rather, we should always err on the side of thinking that there is likely to be much that is valuable that is not yet evident or understood by us. Consider in this context biodiversity loss. Conservation biologists and ecologists agree the rate of species loss is at least 100 and possibly 1000 times faster than background - the fastest mass extinction in the history of the world. But, as the wide margin of uncertainty in the previous sentence reveals, there is so much we do not yet know about the process. Meanwhile, biologists estimate that we may be aware as yet of as few as 1 in 10 species that exist in the world ${ }^{22}$; a far far higher level of ignorance than is present in other sciences such as chemistry. Any financial estimation of the value of biodiversity thus risks direly and systematically understating what is at risk of being lost. The Precautionary Principle would, rightly, force us to lean far more toward safety.

Our vast ignorance of ecology and biology is a serious limit even upon any serious effort to turn economics into science by integrating it with ecology and biology. Given that context, a far better basis for guarding nature at this fateful moment in human history than the fashionable fad for financialisation of nature would be: a serious entrenchment of the Precautionary Principle. And this would bring with it a concomitant great advantage: that precaution simultaneously warns against the reckless pursuit of economic growth. For of course it is still in reality, economic-growthism, and not environmentalism, that actually motivationally underlies most of the dangerous drive toward the economic valuation of so-called 'ecosystem services'.

\section{References}

Beder, Sharon (2002) Global spin: the corporate assault on environmentalism. Totnes: Green Books.

Daly, H. 1996 Beyond Growth (Boston: Beacon).

AQ3 
Ingrao, Bruno and Israel, Giorgio (1990), The invisible hand: Economic Equilibrium in the history of science (Cambridge, Mass: MIT).

Kovel, Joel (2002) The enemy of nature: The end of capitalism or the end of the world? London: Zed.

Philip Mirowski More heat than light: Economics as social physics (Cambridge: C U P, 1989), Against Mechanism: Protecting economics from science (Totowa: Rowman and Littlefield, 1988), and Machine Dreams: Economics becomes a cyborg science (Cambridge: C U P, 2002).

Read, Rupert "Economics is philosophy, economics is not science", International Journal of Green Economics 1: 3/4, 2007.

1 See e.g. my Kuhn (co-authored with Wes Sharrock), Polity Press, 2002.

See my "Wittgenstein and the illusion of progress", Philosophy 78 (July 2016), 265-284.

Or, more strictly, of the conservation of the sum of utility and income. Never mind that the former is unmeasurable, and that the idea of summing the two is simply bizarre and meaningless. Never mind, that is, unless you mind about the foundations of the 'science' of economics. For detailed argument, see for instance Mirowski (1988, 1989, 2002), Ingrao and Israel (1990).

4 See for instance my paper "Economics is philosophy", and my critique of Friedman in my Wittgenstein among the sciences (Ashgate, 2012).

'Including There is no such thing as a social science (co-authored with Phil Hutchinson and Wes Sharrock, 2008, Ashgate). This 'series' reached reached its apogee in my Wittgenstein among the sciences.

${ }_{7}^{6}$ The opening of "The function of measurement in modern physical science", Isis, 52 (2) June 1961, 161-193. Emphases mine.

7 See his "The disunity of science", Mind 92, No. 367 (Jul., 1983), pp. 321-346.

8 For argument to this effect and in-depth further discussion, see pp. 90-1ff. of Kovel's (2002). See also p. $165-6$ and p. 132 of that work, on the interlinkedness of capital's exploitation of nature and of labour.

9 For their sake, we must not pollute more than the Earth (with our help) can sustainably absorb, and we must not use up non-renewable resources unless we are confident that future generations will not need them. For argument as to the policy implications of this, which are I think 'Contraction and Convergence' and a far more egalitarian distribution of resources than that which at present we have, see my paper "Contractarian liberalism cannot take future generations seriously".

${ }^{10}$ Or arguably, in fact, in Wittgenstein's great colleague and influencer, Sraffa (See his The production of commodities by means of commodities, 1960).

${ }_{12}^{11}$ For argument to this conclusion, see Chap. 6 of Beder's (2002). And several of the other essays in this collection.

12 See Gavin Kitching's books on Marx and Wittgenstein for development of this idea.

13 My point here is similar to a central point concerning 'the capital controversy'. You can't measure capital by means of capital, by means ultimately of money. Similarly: you can't measure the contribution of energy to output by means of energy, if everything is in any case 'turned into' energy. In each case, the measuring 'device' then lacks the necessary independence needed for true measurement to occur.

For detailed development of this point, see my "The natural capital controversy", co-authored with Prof. Molly Scott Cato MEP, Journal of Human Rights and the Environment, 5(2), (2014): 153-167.

14 I use the word 'reminder' in Wittgenstein's sense-see PI Sect. 127.

15 See my "Marx and Wittgenstein on vampires and parasites: a critique of capital and metaphysics", in G. N. Kitching \& Nigel Pleasants (eds.), Marx and Wittgenstein: Knowledge, Morality and Politics. Routledge. pp. 35-254 (2002) for discussion of the sense in which Marx demands to be re-read as a philosopher of political economy, rather than as an economist. I suggest there that 'the labour theory of value' is hopeless as scientific economics — and so much the better for it, as philosophy, as a reorientation, that we desperately need, of Marx's readers and followers toward the world of exploitation and inequality that we inhabit.

${ }^{16}$ Take for instance Gowdy's useful https://ideas.repec.org/p/rpi/rpiwpe/0402.html . Gowdy has long nursed the hope of rendering economics truly scientific by basing it in environmental science. I have applauded such hopes-but only if one does not hope to understand or explain love of life or even quality of life through such science alone. "Ecosystem" is in part $a$ value-concept, a normative concept, not reducible to science. That is why in the present paper I have stressed the importance of a role for philosophy, too.

Philosophy can reflect values back to us without loss; science, no matter how 'environmental', cannot.

17 At p.71 of his major piece, "Natural capital and sustainable development", co-authored with Herman Daly, pp.65-74 of his Frontiers in ecological economics (Lyme: Elgar: 1997).

${ }_{19}^{18}$ See again Mirowski's vital oeuvre.

19 My remarks hereabouts are of course strongly influenced by Wittgenstein's conception of philosophy.

${ }^{20}$ See my Liberatory philosophy, forthcoming, and my Wittgenstein among the sciences, op.cit. 
$\angle 1$ In his great work The way.

22 See E O Wilson's book 'Half-Earth'.

23 This paper was made possible by two grants from the AHRC, for the projects on Debating Nature's Value on which I was Principal Investigator, in 2016-18 and in 2019-2020. Thanks, for some comments, to Victor Anderson, and to audiences across Europe, across the years. 